\title{
Reversible Long Term Contraceptives Utilization among Married Women of Reproductive Age Group in Areka town, South Ethiopia
}

\author{
Samson Kastro Dake ( $\nabla$ tasamsona@gmail.com ) \\ Wolaita Sodo University https://orcid.org/0000-0002-7687-4674 \\ Temesgen Lera \\ Wolaita Sodo University
}

\section{Research}

Keywords: Reversible long term contraceptives, Married women, reproductive age group, Utilization, Areka, South Ethiopia

Posted Date: January 6th, 2020

DOI: https://doi.org/10.21203/rs.2.20124/v1

License: (c) (i) This work is licensed under a Creative Commons Attribution 4.0 International License.

Read Full License 


\section{Abstract}

Background: In low income countries, maternal mortality rate remains high. Bearing many children is the main factor affecting maternal health. This study aimed to estimate the prevalence of reversible long term contraceptives utilization and identify factors associated with it among married women of child bearing age in Areka town in South Ethiopia

Methods: We did a community-based cross-sectional survey involving systematically recruited 346 married women of reproductive age group. Data was collected using a structured intervieweradministered questionnaire on May 2019. We used SPSS version 25 for data entry and analyses. Bivariate logistic regression analysis was used to select exposure variables with a crude association. Multivariate analysis was done to control for potential confounders and identify predictors of the outcome. Adjusted Odds Ratio (AOR) with 95\% Confidence Interval (Cl) was reported and statistical significance was declared at $p<0.05$.

Results: The prevalence of reversible long term contraceptives utilization among married women of reproductive age group was $38.7 \%$ in the study area. Utilization of reversible long term contraceptives was positively associated with being Protestant Christian religion follower (AOR=5.33; 95\% Cl: 1.63, 17.40), advanced educational status ( $A O R=5.78 ; 95 \% \mathrm{Cl}: 1.97,17.02)$, history of abortion (AOR=7.17; $95 \%$ Cl: 2.81, 18.27), and having a better attitude towards reversible long term contraceptives (AOR=2.85; 95\% $\mathrm{Cl}: 1.46,5.57)$. Whereas, being a housewife (AOR=.27; $95 \% \mathrm{Cl}$. $09, .79)$ and daily laborer (AOR=.14; $95 \%$ $\mathrm{Cl}: .02, .80)$, having no radio in the household (AOR=.40; $95 \% \mathrm{Cl} . .16, .99)$ and making fertility decisions alone (AOR=.12; $95 \% \mathrm{Cl}$. .04, .37) were negatively associated.

Conclusion: Women should be empowered educationally through other alternative opportunities to school. On top of electronic media, other alternative media should be used to convey messages on contraceptives particularly RLTCs. Behavioral change communications would benefit women in shaping their attitudes towards RLTCs.

\section{Background}

Maternal mortality remains high in most low-income countries. Africa is the region with the highest maternal mortality ratio and Ethiopia is one of the countries which contributed to this high maternal mortality ratio (401 deaths per 100,000 live births) (1). Bearing many children is among the factors which affect maternal health status. Ethiopia is the second most populous country in Africa with a fertility rate of 4.3 (2).

Globally, 190 million women want to avoid pregnancy and do not use any contraceptive method and only $19 \%$ of women rely on Reversible Long Term Contraceptives (RLTC). In sub Saharan Africa, short acting contraceptive methods are most commonly used methods (3). Only $41 \%$ of currently married women use modern methods of family planning and only $11 \%$ are using reversible long term contraceptives (4). 
Despite regional disparities in RLTCs utilization, the documented prevalence across Ethiopia ranges between $12.9 \%$ and $38 \%(5,6)$.

Evidences show that different factors hinder the utilization of RLTCs. Age, contraceptives knowledge, number of pregnancy, desire for more children, educational status, number alive of children, duration of family planning, spousal/partner support, ever use of RLTCs, fear of side effects and source of contraception are some of the reported barriers.

Ethiopia, in the Health Sector Transformation Plan (HSTP V), planned to reduce maternal mortality from 420 to 199 by the end of the year 2020(7). This cannot be achieved without increasing the prevalence of contraceptive utilization, particularly RLTCs. Since there are regional variations in the prevalence and factors associated with RLTCs, evidences are required for appropriate interventions. Thus, this study is aimed at determining the prevalence of RLTCs utilization and identifying factors associated with it.

\section{Methods}

\section{Study setting}

Areka town is one of the seven town administrations in Wolaita zone, south Ethiopia. It is located at $329 \mathrm{~km}$ south from Addis Ababa. The town is administratively structured into 4 kebeles (lower administrative structure) and it has a total population of 33,150 (8). One private hospital, one health center, and seven private clinics provide family planning and other health services to the population in the town.

\section{Study design and period}

A community-based cross-sectional study was conducted in Areka town from May 1 to May 30, 2019.

\section{Population and sampling}

The source population was all married women age 15 to 49 in the town. Systematically recruited 346 mothers were included in the study. Women with a known history of infertility or who use non-reversible contraception were excluded from this study.

A sample size of 352 was calculated using a single population proportion formula with the following assumptions; $95 \%$ confidence level, $5 \%$ margin of error, an estimated prevalence of $29.7 \%$ taken from similar study in south Ethiopia (9) and 10\% non-response rate. Out of 4 kebeles, 2 kebeles were selected randomly and the total sample size was allocated to the selected kebeles proportionally. Households were selected systematically and if the selected household has more than one eligible woman, one was selected randomly.

\section{Measurements}


Eight questions were asked to assess women's knowledge about reversible long term contraceptives. The questions had five Likert scale responses; "Strongly disagree”, "Disagree”, "Not sure”, "Agree” and "Strongly agree". A single variable was established by creating a total score from the questions. Women were categorized as having 'good knowledge' or 'poor knowledge' based on the mean score. Women with a score above the mean were labeled as having "better knowledge", whereas those with a score of the mean or below were labeled as having "poor knowledge".

Similarly, to assess women's attitude towards reversible long term contraceptives, they were asked six Likert scale questions. Women with a score above the mean were categorized as having a "better attitude", whereas those with a score of the mean or below the mean were categorized as having "poor attitude".

\section{Data collection}

Data were collected using a structured interviewer-administered questionnaire. The questionnaire was prepared after reviewing relevant articles and literature. The questionnaire was translated to the local language by fluent speakers of both languages and it was pretested in 18 respondents which were not included in the main study. Data collectors with prior experience of data collection were recruited and trained for two days on the data collection tool and ethics.

\section{Statistical analysis}

Data were entered, cleaned and analyzed by using SPSS version 25. Descriptive statistics were computed for all variables. Binary logistic regression analysis was used to select exposure variables with a crude association to the outcome variable. Hosmer-Lemeshow good-of-fit test was carried out to have confidence in the regression model. Collinearity was diagnosed, and there was no multicollinearity among the exposure variables included in the model. On bivariate analysis, a yardstick cut-off point of p-value less than 0.25 was taken to select candidate variables for multivariate analysis. Multivariate analysis was done to control for potential confounders and identify predictors of the outcome. Adjusted Odds Ratio (AOR) with 95\% Confidence Interval (Cl) was reported and statistical significance was declared at $p$ value $<0.05$.

\section{Results}

\section{Socio-demographic characteristics}

Three hundred forty six women were involved in this study with a response rate of $98.3 \%$. Over three fourth $(261,75.4 \%)$ were aged $20-35$ years and $183(52.9 \%)$ were Protestant Christian religion followers. Seventy-six (22.0\%) women and 56(16.2\%) husbands did not attend formal education. More than half $(189,54.6 \%)$ of the women were housewives whereas $150(43.4 \%)$ of husbands were government/nongovernmental organization (NGO) employees. The majority $(194,56.1 \%)$ of households had an average monthly income of less than 1500 Ethiopian Birr (ETB). More than half $(187,54.0 \%)$ of the households had radio and $246(71.1 \%)$ had a television Table 1$)$. 
Table 1 Socio-demographic characteristics of married women and their husbands at Areka town in South Ethiopia, May 2019 


\begin{tabular}{|c|c|c|c|}
\hline Variables $(n=346)$ & & Frequency & Percent \\
\hline \multirow[t]{3}{*}{ Age (in years) } & $<20$ & 19 & 5.5 \\
\hline & $20-35$ & 261 & 75.4 \\
\hline & $>35$ & 66 & 19.1 \\
\hline \multirow[t]{4}{*}{ Religion } & Orthodox & 97 & 28.0 \\
\hline & Muslim & 35 & 10.1 \\
\hline & Protestant & 183 & 52.9 \\
\hline & Others & 31 & 9.0 \\
\hline \multirow[t]{3}{*}{ Educational status of women } & No formal education & 76 & 22.0 \\
\hline & Primary school (1-8) & 139 & 40.2 \\
\hline & Secondary and above & 131 & 37.8 \\
\hline \multirow[t]{4}{*}{ Educational status of husbands } & No formal education & 56 & 16.2 \\
\hline & Primary school (1-8) & 81 & 23.4 \\
\hline & Secondary school (9-12) & 82 & 23.7 \\
\hline & College and above & 127 & 36.7 \\
\hline \multirow[t]{4}{*}{ Occupation of women } & Government/NGO employee & 50 & 14.5 \\
\hline & Merchant & 83 & 24.0 \\
\hline & Housewife & 189 & 54.6 \\
\hline & Daily laborer & 24 & 6.9 \\
\hline \multirow[t]{4}{*}{ Occupation of husbands } & Government/NGO employee & 150 & 43.4 \\
\hline & Merchant & 109 & 31.5 \\
\hline & Daily laborer & 48 & 13.9 \\
\hline & Other & 39 & 11.3 \\
\hline \multirow[t]{3}{*}{ Household income (ETB) } & $<1500$ & 194 & 56.1 \\
\hline & $1500-3000$ & 62 & 17.9 \\
\hline & $>3000$ & 90 & 26.0 \\
\hline \multirow[t]{2}{*}{ Have radio in the household } & Yes & 187 & 54.0 \\
\hline & No & 159 & 46.0 \\
\hline Have television in the household & Yes & 246 & 71.1 \\
\hline
\end{tabular}




\section{Variables $(n=346)$ \\ Frequency Percent \\ No \\ 100 \\ 28.9 \\ Reproductive health characteristics, knowledge and attitude of women}

One fourth $(88,25.4 \%)$ of the women gave birth to more than five children. Nearly three fourth $(256$, $74.0 \%$ ) had no history of abortion and 202(58.4\%) had a desire for future fertility. The majority (191, $55.2 \%)$ of the couples decide on future fertility jointly. More than half $(182,52.6 \%)$ of the women had better knowledge whereas 154(44.5\%) had a better attitude about RLTC (Table 2).

Table 2 Reproductive characteristics, knowledge and attitude of women involved in the study at Areka town in South Ethiopia, May 2019

\begin{tabular}{|c|c|c|c|}
\hline \multicolumn{2}{|l|}{ Variables $(n=346)$} & \multirow{2}{*}{$\begin{array}{l}\text { Frequency } \\
14\end{array}$} & \multirow{2}{*}{$\begin{array}{l}\text { Percent } \\
4.0\end{array}$} \\
\hline Parity & Nulliparous & & \\
\hline & $1-2$ & 78 & 22.5 \\
\hline & $3-5$ & 166 & 48.0 \\
\hline & $6+$ & 88 & 25.4 \\
\hline \multirow[t]{2}{*}{ History of abortion } & Yes & 90 & 26.0 \\
\hline & No & 256 & 74.0 \\
\hline \multirow[t]{2}{*}{ Future fertility desire } & Yes & 202 & 58.4 \\
\hline & No & 144 & 41.6 \\
\hline \multirow[t]{3}{*}{ Decision maker on future fertility } & Wife & 55 & 15.9 \\
\hline & Husband & 100 & 28.9 \\
\hline & Jointly & 191 & 55.2 \\
\hline \multirow[t]{2}{*}{ Knowledge about RLTC } & Good & 182 & 52.6 \\
\hline & Poor & 164 & 47.4 \\
\hline \multirow[t]{2}{*}{ Attitude on RLTC } & Good & 154 & 44.5 \\
\hline & Poor & 192 & 55.5 \\
\hline
\end{tabular}

\section{Prevalence and predictors of RLTC utilization}

The prevalence of RLTC utilization among married women in this study was $38.7 \%$ (134/346). Protestant religion followers had about five times higher odds of using RLTC (AOR $=5.33 ; 95 \% \mathrm{Cl}: 1.63,17.40)$. 
Women who attended primary education were six times more likely to use RLTCs (AOR $=5.78 ; 95 \% \mathrm{Cl}$ : $1.97,17.02)$, whereas those who attended secondary education and above were seventeen times more likely to use RLTCs (AOR $=16.69 ; 95 \% \mathrm{Cl}: 4.62,60.31)$ compared to those with no formal education. The odds of utilizing RLTCs decreases by $73 \%$ for housewives (AOR $=.27 ; 95 \% \mathrm{Cl}: .09, .79$ ) and by $86 \%$ for daily laborers compared to government and NGO employees (AOR $=.14 ; 95 \% \mathrm{Cl}$ : .02, .80).

The odds of using RLTCs decreases by $60 \%$ for women who don't have a radio in the household (AOR $=.40 ; 95 \% \mathrm{Cl}: .16, .99)$. Women who had a history of abortion were seven times more likely to use RLTCs ( $A O R=7.17 ; 95 \% \mathrm{Cl}: 2.81,18.27)$. On the other hand, women who decide alone on future fertility were $88 \%$ less likely to use RLTCs compared with those who decide jointly (AOR $=.12 ; 95 \% \mathrm{Cl}$. .04, .37). Women with a better attitude about RLTCs are three times more likely to utilize RLTCs (AOR $=2.85 ; 95 \%$ Cl: $1.46,5.57)$ (Table 3). 
Table 3

Factors associated with reversible long term contraceptive utilization in Areka town, South Ethiopia, May 2019

\begin{tabular}{|c|c|c|c|c|}
\hline \multirow[t]{2}{*}{ Variable $(n=346)$} & \multicolumn{2}{|c|}{ RLTC utilization } & \multirow[t]{2}{*}{$\operatorname{COR}(96 \% \mathrm{Cl})$} & \multirow[t]{2}{*}{ AOR $(95 \% \mathrm{Cl})$} \\
\hline & Yes & No & & \\
\hline \multicolumn{5}{|l|}{ Religion } \\
\hline Muslim & 11(31.4) & $24(68.8)$ & 1 & 1 \\
\hline Orthodox & $45(46.4)$ & $52(53.6)$ & $1.89(.83,4.28)$ & $1.02(.29,3.65)$ \\
\hline Protestant & $69(37.7)$ & $114(62.3)$ & $1.32(.61,2.86)$ & $5.33(1.63,17.40)^{\star \star}$ \\
\hline Others & $9(29.0)$ & $22(71.0)$ & $.89(.31,2.56)$ & $2.95(.67,13.09)$ \\
\hline \multicolumn{5}{|l|}{ Education of women } \\
\hline No formal education & $9(11.8)$ & $67(88.2)$ & 1 & 1 \\
\hline Primary school (1-8) & $52(37.4)$ & $87(62.6)$ & $4.45(2.05,9.67)$ & $5.78(1.97,17.02)^{\star \star}$ \\
\hline Secondary and above & 73(55.7) & $58(44.3)$ & $9.37(4.31,20.37)$ & $16.69(4.62,60.31)^{\star \star}$ \\
\hline \multicolumn{5}{|l|}{ Occupation of women } \\
\hline Gov't/NGO employee & $27(54.0)$ & $23(46.0)$ & 1 & 1 \\
\hline Merchant & $49(59.0)$ & $34(41.0)$ & $1.23(.61,2.49)$ & $1.40(.45,4.38)$ \\
\hline Housewife & $51(27.0)$ & 138(73.0) & $.32(.17, .60)$ & $.27(.09, .79)^{\star \star}$ \\
\hline Daily laborer & $7(29.2)$ & 17(70.8) & $.35(.12, .99)$ & $.14(.02, .80)^{\star \star}$ \\
\hline \multicolumn{5}{|c|}{ Occupation of husbands } \\
\hline Gov't/NGO employee & $74(49.3)$ & $76(50.7)$ & 1 & 1 \\
\hline Merchant & $36(33.0)$ & $73(67.0)$ & $.51(.30, .85)$ & $.47(.14,1.56)$ \\
\hline Daily laborer & $7(14.6)$ & $41(85.4)$ & $.18(.07, .42)$ & $.20(.04,1.11)$ \\
\hline Other & $17(43.6)$ & $22(56.4)$ & $.79(.39,1.61)$ & $.65(.13,3.31)$ \\
\hline \multicolumn{5}{|l|}{ Household income } \\
\hline$<1500$ & $59(30.4)$ & $135(69.6)$ & 1 & 1 \\
\hline $1500-3000$ & $29(46.8)$ & $33(53.2)$ & $2.01(1.12,3.61)$ & $2.22(.70,7.06)$ \\
\hline$>3000$ & $46(51.1)$ & $44(48.9)$ & $2.39(1.43,4.00)$ & $1.17(.37,3.73)$ \\
\hline
\end{tabular}




\begin{tabular}{|c|c|c|c|c|}
\hline \multirow[t]{2}{*}{ Variable $(n=346)$} & \multicolumn{2}{|c|}{ RLTC utilization } & \multirow[t]{2}{*}{$\operatorname{COR}(96 \% \mathrm{Cl})$} & \multirow[t]{2}{*}{ AOR (95\% Cl) } \\
\hline & Yes & No & & \\
\hline Yes & $66(35.3)$ & $121(64.7)$ & 1 & 1 \\
\hline No & $68(42.8)$ & $91(57.2)$ & $1.37(.89,2.12)$ & $1.52(.77,3.01)$ \\
\hline \multicolumn{5}{|c|}{ Have television in the $\mathrm{HH}$} \\
\hline Yes & $101(41.1)$ & $145(58.9)$ & 1 & 1 \\
\hline No & $33(33.0)$ & $67(67.0)$ & $.71(.43,1.15)$ & $.40(.16, .99)^{\star \star}$ \\
\hline \multicolumn{5}{|l|}{ Parity } \\
\hline Nulliparous & $5(35.7)$ & $9(64.3)$ & $1.10(.35,3.47)$ & $.54(.08,3.45)$ \\
\hline $1-2$ & $28(35.9)$ & $50(64.1)$ & $1.12(.62,2.00)$ & $.50(.19,1.32)$ \\
\hline $3-4$ & $56(46.7)$ & 64(53.3) & $1.73(1.04,2.87)$ & $1.52(.67,3.45)$ \\
\hline $5+$ & 45(33.6) & $89(66.4)$ & 1 & 1 \\
\hline \multicolumn{5}{|l|}{ History of abortion } \\
\hline Yes & 14(15.6) & $76(84.4)$ & $.21(.11, .39)$ & $7.17(2.81,18.27)^{\star \star}$ \\
\hline No & $120(46.9)$ & $136(53.1)$ & 1 & 1 \\
\hline \multicolumn{5}{|c|}{ Decision maker on fertility } \\
\hline Wife & 13(23.6) & 42(76.4) & $.58(.35, .96)$ & $.12(.04, .37)^{\star \star}$ \\
\hline Husband & 33(33.0) & $67(67.0)$ & $.36(.18, .72)$ & $.77(.34,1.78)$ \\
\hline Jointly & $88(46.1)$ & 103(53.9) & 1 & 1 \\
\hline \multicolumn{5}{|c|}{ Knowledge about RLTC } \\
\hline Good & $49(26.9)$ & 133(73.1) & $.34(.22, .54)$ & $1.02(.46,2.27)$ \\
\hline Poor & $85(51.8)$ & $79(48.2)$ & 1 & 1 \\
\hline \multicolumn{5}{|c|}{ Attitude about RLTC } \\
\hline Good & $40(26.0)$ & $114(74.0)$ & $.37(.23, .58)$ & $2.85(1.46,5.57)^{\star \star}$ \\
\hline Poor & $94(49.0)$ & $98(51.0)$ & 1 & 1 \\
\hline
\end{tabular}

\section{Discussion}

This study documented that about $38.7 \%$ of married women in the reproductive age group use RLTCs. We observed higher prevalence in the current study as compared to similar studies in Ethiopia, Indonesia and 
elsewhere $(5,6,10-13)$. This difference might be due to the socio-demographic variability in the study areas, where all of our study participants were from urban who might have more access to family planning information. A comparable prevalence was reported from Eastern Ethiopia (14).

Protestant Christian religion followers had much higher odds of using RLTCs as compared to their Muslim counterparts. This finding is supported by a study conducted in Nigeria, where the use of contraceptives was significantly lower among Muslim women as compared to women from other religions (15). This might be due to the belief that contraceptives use contradicts with Islam teaching because Islam encourages Muslims to give birth to many children $(16,17)$. Another possible reason is that polygamy is permitted in Islam and most of the women in polygamous marriage believe that they can win the attention of their husband's when they often get pregnant for him(18).

In consistence with studies from different parts of Ethiopia and Zambia, RLTC utilization increased with advanced educational status $(6,19-21)$. This might be because advanced educational status increased the aware of women on the benefits of RLTCs. The decision making power is also higher for women with a better education. A different finding was reported from Indonesia, where no significant association was reported between educational status and RLTCs utilization (13). This difference might be due to the small sample size used in the above study.

The utilization of RLTCs was lower for housewives and daily laborers in comparison to government or NGO employees. This finding is consistent with other studies from Ethiopia where government employees were more likely to utilize RLTCs $(11,22)$. The possible explanation might be that government and NGO employees have a better educational status and in turn better access to information.

In consistence with studies in Ethiopia and central Asia, the utilization of RLTCs was lower for those who do not have a radio in the household compared to their counterparts $(11,23)$. The possible reason might be that listening to family planning messages through electronic media had improved the chance of using RLTCs (24).

We observed that women with a history of abortion had higher odds of using RLTCs. Similarly, a study from Angola reported that women with a history of abortion were more likely to use modern family planning compared to women who never had an abortion(25). The possible reasons might be access for LTRCs and health education given at health facilities as part of post-abortion care (PAC).

Compared to women who decide jointly with their partners, women who decide alone on fertility had lower odds of using RLTCs. This was in agreement with studies in Ethiopia, Zambia, and Uganda, where women who discuss with husbands were more likely associated with RLTCs utilization $(10,11,26-30)$. Women with a better attitude towards RLTCs had much higher odds of using RLTCs than their counterparts. This finding is consistent with other studies from Ethiopia $(26,31,32)$.

\section{Limitations of the study}


We used cross-sectional data and a cause-effect relationship could not be measured.

\section{Conclusion}

Women should be empowered educationally through other alternative opportunities to school, for the reason that it would or would not be possible to bring all married women to school. On top of electronic media, other alternative media should be used to convey messages on contraceptives particularly RLTCs. Programs working on contraceptives utilization should also encourage spousal communication. Behavioral change communications would benefit women in shaping their attitudes towards RLTCs.

\section{Declarations}

Ethics approval and consent to participate

Ethical clearance for the study was obtained from the Ethical review committee at the College of Health Science and Medicine in Wolaita Sodo University in Ethiopia. The ethical clearance letter was written to the Wolaita zone health department. Permission to conduct the study was granted from the Wolaita zone health department and Areka town health office. Finally, informed written consent was taken from the study participants.

Consent for publication-Not applicable

\section{Availability of data and materials}

The dataset analyzed for this study is available from the corresponding author on reasonable request.

\section{Competing interests}

The authors declare that they have no competing interests.

Funding: No funding was received from any party to conduct or publish this study.

\section{Authors' contributions}

SK and TL conceived the study, designed the protocol, coordinated data collection, analyzed the data, and interpreted the findings. SK drafted the manuscript and TL reviewed the progressive draft manuscript. Both authors read and approved the final version of the manuscript.

\section{Authors' information}

SK is a human nutritionist by training. He is a lecturer at the School of Public Health at WSU. TL is a reproductive health specialist by training. He is a lecturer at the School of Public Health at WSU.

\section{Acknowledgments}


We are grateful to Wolaita Sodo University and particularly the School of Public Health at Wolaita Sodo University for facilitating the research program. We acknowledge the Wolaita zone health department and Areka town health office for official permission. We are also grateful to the study participants for their consent to participate in the study. We also thank our responsible data collectors.

\section{Abbreviations}

AOR: Adjusted Odds Ratio; Cl: Confidence Interval; COR: Crude Odds Ratio; ETB: Ethiopian Birr; NGO: NonGovernment Organization; PAC: Post Abortion Care; RLTC: Reversible Long Term Contraceptives; SPSS: Statistical Package for Social Science; WSU: Wolaita Sodo University

\section{References}

1. Maternal mortality estimates [database on the Internet]. 2019 [cited 12/23/2019]. Available from: http://apps.who.int/gho/data/view.main.1370?lang=en.

2. Bank W. Fertility rate, total (births per woman) - Ethiopia. 2019.

3. Nations U. Contraceptive use by method 2019:Data booklet. Affairs DoEaS; 2019.

4. Institute EPH, ICF. Ethiopia Mini Demographic and Health Survey 2019: Key Indicators. Rockville, Maryland, USA: EPHI ICF; 2019.

5. Getahun DS, Wolde HF, Muchie KF, Yeshita HY. Utilization and determinants of long term and permanent contraceptive methods among married reproductive age women at Janamora district, northwest Ethiopia. BMC Res Notes. 2018;11(1):836. Epub 2018/11/28.

6. Zenebe CB, Adefris M, Yenit MK, Gelaw YA. Factors associated with utilization of long-acting and permanent contraceptive methods among women who have decided not to have more children in Gondar city. BMC women's health. 2017;17(1):75. Epub 2017/09/08.

7. Group WB. Ethiopia Health Sector Transformation Plan (2015/16-2019/20). In: Health EMo, editor. 2015.

8. Review WP. Population of Cities in Ethiopia (2019). 2019 [cited 2019 11/12/2019]; Available from: http://worldpopulationreview.com/countries/ethiopia-population/cities/.

9. Kabalo MY. Utilization of reversible long acting family planning methods among married 15-49 years women in Areka town, Southern Ethiopia. International Journal of Scientific Reports. 2016;2(1).

10. Tesfa E, Gedamu H. Factors associated with utilization of long term family planning methods among women of reproductive age attending Bahir Dar health facilities, Northwest Ethiopia. BMC Res Notes. 2018;11(1):926. Epub 2018/12/28.

11. Melka AS, Tekelab T, Wirtu D. Determinants of long acting and permanent contraceptive methods utilization among married women of reproductive age groups in western Ethiopia: a cross-sectional study. Pan Afr Med J. 2015;21:246. Epub 2015/11/03. 
12. Alemayehu M, Belachew T, Tilahun T. Factors associated with utilization of long acting and permanent contraceptive methods among married women of reproductive age in Mekelle town, Tigray region, north Ethiopia. BMC Pregnancy Childbirth. 2012;12:6. Epub 2012/01/28.

13. Harzif AK, Mariana A, Malik DM, Silvia M, Lovita BT. Factors associated with the utilization of longacting reversible contraceptives among family planning clients at the Pameungpeuk Rural Hospital, Indonesia. F1000Res. 2018;7:1891. Epub 2019/11/26.

14. Shiferaw K, Musa A. Assessment of utilization of long acting reversible contraceptive and associated factors among women of reproductive age in Harar City, Ethiopia. Pan Afr Med J. 2017;28:222. Epub 2018/04/10.

15. Obasohan PE. Religion, Ethnicity and Contraceptive Use among Reproductive age Women in Nigeria. Int J MCH AIDS. 2015;3(1):63-73. Epub 2015/01/01.

16. Sakara A, Y.Namoog M, Badu-Nyarko SK. Misconceptions and rumours about family planning among Moslem males in Tamale Metropolis, Ghana. Global Journal of Interdisciplinary Social Sciences. 2015;4(1):9-14.

17. Wasti SP, Simmons R, Limbu N, Chipanta S, Haile L, Velcoff J, et al. Side-Effects and Social Norms Influencing Family Planning Use in Nepal. Kathmandu University medical journal (KUMJ). 2017;15(59):222-9. Epub 2017/07/01.

18. Lakew Y, Reda AA, Tamene H, Benedict S, Deribe K. Geographical variation and factors influencing modern contraceptive use among married women in Ethiopia: evidence from a national population based survey. Reproductive health. 2013;10(52):1742-4755.

19. Bakibinga P, Matanda D, Kisia L, Mutombo N. Factors associated with use of injectables, long-acting and permanent contraceptive methods (iLAPMs) among married women in Zambia: analysis of demographic and health surveys, 1992-2014. Reproductive health. 2019;16(1):78. Epub 2019/06/07.

20. Habtamu A, Tesfa M, Kassahun M, Animen S. Determinants of long-acting contraceptive utilization among married women of reproductive age in Aneded district, Ethiopia: a case-control study. BMC Res Notes. 2019;12(1):433. Epub 2019/07/20.

21. Animen S, Lake S, Mekuriaw E. Utilization of intra uterine contraceptive device and associated factors among reproductive age group of family planning users in Han Health Center, Bahir Dar, North West Amhara, Ethiopia, 2018. BMC Res Notes. 2018;11(1):922. Epub 2018/12/24.

22. Kebede Y. Contraceptive prevalence in Dembia District, northwest Ethiopia. Ethiopian Journal of Health Development. 2006;20(1):32-8.

23. Dasa TT, Kassie TW, Roba AA, Wakwoya EB, Kelel HU. Factors associated with long-acting family planning service utilization in Ethiopia: a systematic review and meta-analysis. Contraception and reproductive medicine. 2019;4:14. Epub 2019/10/05.

24. Habibov $\mathrm{N}$, Zainiddinov $\mathrm{H}$. Effect of TV and radio family planning messages on the probability of modern contraception utilization in post-Soviet Central Asia. Int J Health Plann Manage. 2017;32(1):e17-e38. Epub 2015/10/23. 
25. Morris N, Prata N. abortion history and its association with current use of modern contraceptive methods in Luanda, Angola. Open Access Journal of Contraception. 2018;2018(9):45-55.

26. Aregay W, Azale T, Sisay M, Gonete KA. Utilization of long acting reversible contraceptive methods and associated factors among female college students in Gondar town, northwest Ethiopia, 2018: institutional based cross-sectional study. BMC Res Notes. 2018;11(1):862. Epub 2018/12/07.

27. Yalew SA, Zeleke BM, Teferra AS. Demand for long acting contraceptive methods and associated factors among family planning service users, Northwest Ethiopia: a health facility based cross sectional study. BMC Res Notes. 2015;8(29):015-0974.

28. Mutombo N, Bakibinga P. The effect of joint contraceptive decisions on the use of Injectables, LongActing and Permanent Methods (ILAPMs) among married female (15-49) contraceptive users in Zambia: a cross-sectional study. Reproductive health. 2014;11:51. Epub 2014/07/06.

29. Anguzu R, Tweheyo R, Sekandi JN, Zalwango V, Muhumuza C, Tusiime S, et al. Knowledge and attitudes towards use of long acting reversible contraceptives among women of reproductive age in Lubaga division, Kampala district, Uganda. BMC Res Notes. 2014;7:153. Epub 2014/03/19.

30. Earsido A, Gebeyehu A, Kisi T. Determinants of long acting and permanent contraceptive methods utilization among married women in Hossana town, Southern Ethiopia: A case-control study. Journal of Pregnancy and Child Health. 2015;2(165).

31. Meleko A, Sileshi S, Bekele Y, Daniel A, Getawey A, Amare D, et al. Utilization of long acting reversible contraceptive methods and its associated factors among women of reproductive age group in Mizan-Aman town, Bench Maji zone, southwest Ethiopia. Journal of Womens Health, Issues and Care. 2017;6(6).

32. Desalegn M, Belachew A, Gizaw M, Kejela G, Gudeta R. Utilization of long-acting and permanent contraceptive methods and associated factors among married women in Adama town, Central Ethiopia: a community based cross-sectional study. Contraception and reproductive medicine. 2019;4(22).

\section{Supplementary Files}

This is a list of supplementary files associated with this preprint. Click to download.

- completedSTROBEcrosssectionalchecklist.docx 